\title{
CONTABILIDADE DESPORTIVA: UM ESTUDO SOBRE O IMPACTO DOS INVESTIMENTOS NA FORMAÇÃO DE ATLETAS NAS MARCAS DOS CLUBES BRASILEIROS DE FUTEBOL
}

\section{SPORTS ACCOUNTING: A STUDY ON THE IMPACT OF INVESTMENTS IN TRAINING ATHLETES ON THE BRANDS OF BRAZILIAN SOCCER CLUBS}

\begin{abstract}
RESUMO
Recentemente, muitos estudos contribuíram para o campo da Contabilidade Desportiva, especialmente no tocante ao futebol. Majoritariamente, tais estudos são qualitativos e focam nos custos de formação dos atletas. Fugindo do escopo tradicional, este trabalho objetiva identificar, através de uma abordagem quantitativa, se há relação positiva entre os investimentos feitos nas categorias de base e o valor das marcas dos clubes brasileiros de futebol. Para tal, foi utilizada a técnica de análise de regressão, tendo como variável dependente o valor das marcas dos clubes, obtido em estudo específico da empresa BDO, e como variável preditora os custos de atletas em formação, coletados diretamente dos demonstrativos publicados pelos clubes. A amostra final contém 66 observações que remetem aos clubes da Série A do futebol brasileiro, entre os anos de 2013 e 2016. Os resultados apontam um poder de explicação de, aproximadamente, $34 \%$ do valor das marcas através dos investimentos feitos nas categorias de base, sendo o modelo gerado estatisticamente significativo a um nível de $99 \%$ de confiança. Com tais resultados, foi possível atestar que os investimentos nas categorias de base possuem relação positiva com o valor das marcas dos clubes, corroborando os achados de estudos anteriores de que gastos na formação de atletas são verdadeiros investimentos para os clubes. Complementarmente, foi verificado, através de testes de diferença de médias, que existe diferença estatisticamente significativa no valor das marcas dos clubes e no nível de investimentos feitos nas categorias de base de acordo com as regiões geográficas dos clubes.
\end{abstract}

Palavras-chave: Custo de Formação de Atletas; Ativo Intangível; Contabilidade Desportiva.

\section{ABSTRACT}

Recently, many studies have contributed to the field of Sports Accounting, especially in football. Majorly, such studies are qualitative and focus on the training costs of athletes. Evading the traditional scope, this work aims to identify through a quantitative approach if there is a positive relation between the investments made in the basic categories and the value of the brands of the Brazilian soccer clubs. For this, the regression analysis technique was used, having as dependent variable the value of club brands, obtained in a specific study of the company $\mathrm{BDO}$ and as a predictor variable the costs of athletes in training, collected directly from the statements published by the clubs. The final sample contains 66 observations that refer to Brazilian A Series clubs between the years of 2013 and 2016. Results showed an explanation power of approximately $34 \%$ of the value of brands through investments made in the basic categories, being the generated model statistically significant at $99 \%$ level of confidence. With these results, it was possible to confirm that the investments in the basic categories have a positive relation with the value of the clubs' brands, corroborating the findings of previous studies that spending on the training of athletes are real investments for the clubs. In addition, it was verified through means difference tests that there is a statistically significant difference in the value of the clubs' brands and in the level of investments made in the base categories according to the geographic regions of the clubs.

\section{Ronan Reis Marçal}

Mestrando em Ciências Contábeis pela Universidade Federal do Rio de Janeiro (UFRJ). Graduado em Ciências Contábeis pelo Centro Universitário Carioca (Unicarioca). Contato: Rua Upiara, 373, Bento Ribeiro, Rio de Janeiro, RJ, CEP: 21.331-400.

E-mail:m.ronanreis@gmail.com

Keywords: Athletes Training Cost; Intangible Assets; Sports Accounting. 


\section{INTRODUÇÃO}

As práticas esportivas de alto nível competitivo deixaram o âmbito meramente desportivo e foram devidamente reconhecidas como atividades de relevante importância econômica, de acordo com Liszbinski et al. (2012). Tratando especificamente sobre o futebol, Matos et al. (2015) confirmam tal entendimento ao explicar que esse esporte adquiriu um status de negócio.

Conforme Lopes e Davis (2006), o futebol é o esporte mais popular do Brasil e, dada essa relevância econômico-financeira, muitos estudos foram feitos acerca das práticas contábeis dos clubes brasileiros, com especial enfoque na classificação e evidenciação do patrimônio desses clubes. Muitos dispositivos legais e normas contábeis sobre a contabilização de entidades desportivas foram atualizados durante o final do século XX e o início do século XXI, gerando uma grande gama de estudos sobre o tema nesse período. Alguns estudos, como o de Bastos, Pereira e Tostes (2007), encontraram falta de padronização das publicações dos clubes de futebol brasileiro durante esse período.

É importante ressaltar que, embora a literatura nacional e internacional acerca do tema seja vasta, os estudos são majoritariamente qualitativos e, em geral, do tipo pesquisa exploratória ou análise documental (PATON et al., 2013).

Com a relevância do tema proposto e a lacuna metodológica existente neste cerne, surge a motivação deste estudo. O objetivo é verificar se os investimentos feitos nas categorias de base pelos clubes brasileiros de futebol possuem relação positiva com o valor das marcas de tais clubes. Com isso, será possível aceitar ou confrontar a ideia de que investimentos nas categorias de base trazem retorno financeiro aos clubes. O recurso metodológico a ser utilizado para tal é a análise de regressão, que está inserida no campo das pesquisas quantitativas (CORRAR; PAULO; DIAS FILHO, 2007).

A amostra é do tipo não probabilística, segundo Gujarati e Porter (2011), uma vez que os dados referentes à variável dependente bem como aqueles referentes à variável independente foram previamente selecionados e coletados de outras fontes. Tal amostra está delimitada aos clubes da série A do campeonato brasileiro de futebol, entre os anos de 2013 e 2016.

É esperado que este estudo ajude a suprir a lacuna quantitativa da literatura sobre Contabilidade Desportiva aplicada ao futebol e que, com aos resultados obtidos, possam ser confirmados ou contestados os achados anteriores de outras pesquisas neste âmbito.

O trabalho está segmentado em cinco partes, sendo a seguinte a que remonta ao referencial teórico do tema proposto. Em sequência, dar-se-ão o percurso metodológico proposto bem como a análise dos resultados obtidos. Por fim, serão apresentadas as conclusões do autor, as possíveis limitações do estudo e, ainda, sugestões para trabalhos posteriores.

\section{REFERENCIAL TEÓRICO}

\subsection{Contabilidade Desportiva e os clubes de futebol no Brasil}

O futebol é o esporte mais popular do Brasil. Graças ao desempenho obtido em competições internacionais por clubes e pela Seleção Brasileira, o futebol nacional tornou-se referência de prática desportiva, culminando em um grande número de estudos acerca de sua legislação e afins (GALINDO, 2016).

O futebol, já há algum tempo, não é mais observado meramente como um desporto, uma vez que sua magnitude implica em grandes quantias de recursos que são mobilizadas por clubes e sócios em transações diversas, gerando um efetivo impacto econômico (BASTOS; PEREIRA; TOSTES, 2007; LISZBINSKI et al., 2012).

Corroboram com essa visão Matos et al. (2015), ao afirmarem que o futebol é um dos esportes mais populares do mundo e, cada vez mais, se consolida como um verdadeiro negócio, e Galindo (2016), que afirma ser o futebol um excelente campo para a obtenção de lucros por parte de investidores.

De acordo com Buesa e Araújo (2012), a primeira norma a tratar especificamente sobre entidades desportivas foi o Decreto-Lei n. ${ }^{\circ} 3.199$, de 1941, que não permitia a obtenção de lucros por parte de tais entidades. Essa limitação foi vigente até o ano de 1993, quando foi decretada a Lei n. ${ }^{\circ} 8.672$, conhecida como Lei Zico, que permitia a transformação de clubes em sociedades comerciais (HOLANDA et al., 2012).

Já em 1998, através da Lei n. ${ }^{\circ}$ 9.615, chamada de Lei Pelé, as entidades foram obrigatoriamente equiparadas a sociedades comerciais, de acordo com Liszbinski et al. (2012) e Paton et al. (2013), contudo, essa obrigatoriedade passou a ser uma mera opção com o advento da Lei n. ${ }^{\circ}$ 10.672/03 (REZENDE; FACURE; DALMÁCIO, 2009).

Dado este aparato, para Araújo et al. (2013), os clubes brasileiros de futebol são considerados sociedades civis de caráter desportivo, social e cultural. Para que consigam cumprir suas funções, os clubes precisam de um conjunto de atletas capacitados tecnicamente, sendo estes, portanto, os elementos mais importantes para os clubes (CRUZ, 2007).

Em muitos países da Europa, diferentemente, os clubes de futebol são tratados como sociedades empresariais (PATON et al., 2013). Isso pode ter alguma relação com a afirmação de Curvina e Nascimento (2014) de que a gestão dos clubes brasileiros é amadora, prejudicando a identificação, a classificação e a mensuração de seus principais ativos: os jogadores.

De acordo com a definição presente no item 4.4 da estrutura conceitual para elaboração e divulgação de relatório contábil-financeiro disposta pelo Comitê de Pronunciamentos Contábeis (CPC), um ativo é um recurso controlado pela entidade, decorrente de eventos passados, do qual se espera que fluam benefícios econômicos futuros para a entidade.

Os jogadores de futebol contribuem para a geração de receitas dos clubes através de suas participações nas partidas que podem culminar em premiações de competições e, também, atrair mais torcedores aos estádios, gerando uma maior renda de bilheteria. Além disso, podem aumentar o número de vendas de produtos licenciados dos clubes atrelados aos seus direitos de imagem (LOPES; DAVIS, 2006). 
Como os jogadores estão vinculados aos clubes mediante contrato, podem ser considerados recursos controláveis e, dado que, em algum momento do passado, um jogador obrigatoriamente foi contratado junto a outro clube ou formado dentro do próprio clube, há, também, a presença da decorrência de eventos passados (MATOS et al., 2015).

Visto que todas as características exigidas para a definição de ativo são claramente satisfeitas, não há dúvidas quanto à sua classificação. Lopes e Davis (2006) confirmam este entendimento ao afirmarem que ativar os jogadores de futebol é um procedimento que atende perfeitamente à Teoria Contábil.

Com relação aos contratos dos jogadores de futebol com os clubes, é importante salientar uma grande mudança decorrente da Lei Pelé: a extinção do "passe" (HOLANDA et al., 2012; LOPES; DAVIS, 2006; SILVA; MORAES, 2010).

Antes do advento de tal lei, o vínculo dos jogadores com os clubes era conhecido como passe, que representava uma relação de moldes medievais, conforme Galindo (2016), na qual os jogadores eram tratados como verdadeiras mercadorias. Buesa e Araújo (2012) explicam que apenas em 1964, através do Decreto-Lei n. ${ }^{\circ}$ 53.820, os jogadores passaram a deter, ao menos, uma participação no preço de seus passes.

O passe foi, então, substituído pelos chamados "direitos federativos" que, diferentemente do primeiro, possuem a característica de temporariedade através do prazo de vigência do contrato (CURVINA; NASCIMENTO, 2014). De acordo com Lopes e Davis (2006), o termo mais adequado a ser utilizado seria “direito de vínculo desportivo". Cabe ressaltar, ainda, que o passe deveria ser extinto em até três anos e, para tal, foram adotados procedimentos contábeis diversos à época (BUESA; ARAÚJO, 2012).

É mister diferenciar os direitos federativos dos direitos econômicos. Enquanto aquele remete ao direito do clube de registrar determinado jogador na Federação de forma exclusiva para fins desportivos, esse decorre justamente da venda dos direitos federativos para outros clubes em eventuais transações (CRUZ; SANTOS; AZEVEDO, 2010; CURVINA; NASCIMENTO, 2014).

A contabilização não é do jogador em si, considerado como um item ao invés de um ser humano, mas sim do direito do clube de usufruir dos benefícios econômicos futuros advindos do jogador (CRUZ, 2007). De acordo com essa fundamentação, Curvina e Nascimento (2014) entendem que, por serem as habilidades técnicas, intelectuais e sociais dos jogadores elementos não revestidos da característica de tangibilidade, devem os jogadores ser registrados no grupo dos ativos intangíveis.

A norma vigente para as entidades desportivas profissionais, a Interpretação Técnica Geral 2003 (ITG 2003), considera, de fato, os jogadores como ativos intangíveis, mas isso nem sempre foi assim. Antes mesmo da convergência das normas contábeis internacionais, através da Lei n. ${ }^{\circ} 11.638 / 2007$, já havia um dispositivo legal que indicava como deveriam ser classificados os jogadores de futebol por seus clubes.

Essa norma era a Norma Brasileira de Contabilidade Técnica 10.13 (NBC T 10.13), aprovada pela Resolução do Conselho Federal de Contabilidade (CFC) n. ${ }^{\circ}$ 1.005/2004, cujo texto apontava a necessidade de classificar os jogadores no grupo do ativo imobilizado. Após a convergência, essa norma não foi atualizada e, com o advento de novos dispositivos legais, tal classificação foi alterada para o grupo dos ativos intangíveis, de acordo com o Pronunciamento Técnico CPC 04 (ARAÚJO et al., 2013; CURVINA; NASCIMENTO, 2014; LISZBINSKI et al., 2012).

Araújo et al. (2013) acreditam que os ativos intangíveis são sempre elementos de considerável importância para quaisquer entidades e, tratando-se de clubes de futebol, essa relevância é ainda maior. Curvina e Nascimento (2014), por sua vez, entendem que os ativos intangíveis, por vezes, são rejeitados em virtude de sua não verificabilidade corpórea, mas, devido à sua materialidade dentro dos clubes de futebol, são considerados itens fundamentais para a geração de receitas.

Um outro importante impacto contábil nas entidades desportivas foi a padronização das publicações dos demonstrativos contábeis através da NBC T 10.13, visto que eram recorrentes as inconformidades das publicações antes de tal norma (BASTOS; PEREIRA; TOSTES, 2007; HOLANDA et al., 2012).

\subsection{Custo na formação de atletas}

Teoricamente, os clubes de futebol deveriam sustentar suas atividades através de contribuições dos sócios, rendas de bilheteria, patrocínios e direitos de imagem de suas marcas (LOPES; DAVIS, 2006). Todavia, o que ocorre é que, devido aos elevados valores envolvendo a negociação de atletas, clubes brasileiros passaram a investir mais nas categorias de base, tratando a receita de vendas de jogadores como uma das principais fontes de recursos dos clubes. Isso vem causando, inclusive, um processo no qual chegam ao elenco dos profissionais atletas cada vez mais jovens (CRUZ, 2012).

Os gastos nas categorias de base são feitos visando formar atletas que servirão ao clube na categoria dos profissionais ou, ainda, poderão ser negociados com outros clubes, trazendo receitas aos cofres (ARAÚJO et al., 2013; HOLANDA et al., 2012).

O processo de formação de atletas é demorado e complexo, além de ser deveras arriscado em função das potenciais lesões que os atletas podem vir a sofrer, conforme Galindo (2016). Além disso, devido a tais dificuldades, é necessário que as entidades formadoras sejam bem estruturadas e organizadas para que o processo ocorra de forma correta (BASTIDAS; BASTOS, 2011).

A apuração do custo de qualquer atleta é de fundamental importância para os clubes de futebol, ao passo que demonstra, a qualquer tempo, os investimentos feitos nos atletas (SILVA; MORAES, 2010). Não é diferente a tratativa com os custos específicos de formação de atletas, já que estes representam significante parcela de lucratividade dos clubes de futebol (MATOS et al., 2015).

De acordo com Cruz (2007), esse custo de formação deverá representar fidedignamente os sacrifícios feitos pelos clubes ao objetivarem conduzir tecnicamente e socialmente os jovens atletas ao grupo dos atletas profissionais. Gastos 
com observações, locais para treinamento e treinadores são comuns gastos destinados às categorias de base (CRUZ; SANTOS; AZEVEDO, 2010).

Embora a NBC T 10.13 não tenha sido atualizada, mantendo em seu texto, ainda, a indicação de classificação no grupo do Imobilizado, é relevante comentar que nela é mencionada a rubrica contábil adequada para a formação de atletas. Inicialmente, deverão ser tratados os custos sob a nomenclatura "atletas em formação" e, quando ativados, serão estes valores tratados como "atletas formados", sendo amortizados pelos prazos dos contratos (BASTOS; PEREIRA; TOSTES, 2007; CRUZ; SANTOS; AZEVEDO, 2010; LISZBINSKI et al., 2012).

Segundo Lopes e Davis (2006), devido à incerteza da geração de benefícios econômicos futuros decorrentes de atletas em formação, é comum haver dúvidas quanto à classificação destes gastos. Para Cruz (2007), como os contratos com os atletas da base só podem ser feitos a partir dos 16 anos, todos os recursos aplicados em atletas antes dessa idade devem ser tratados como gastos do período, de forma análoga aos gastos com pesquisa e desenvolvimento.

Havendo dispensa do jovem atleta durante o processo de formação ou desistência do mesmo, os custos são considerados como despesas do período, de acordo com os ensinamentos de Silva e Moraes (2010). Similarmente, no encerramento de cada exercício, poderá ser feito o mesmo procedimento contábil (CRUZ; SANTOS; AZEVEDO, 2010).

Há de se mencionar, ainda, algumas especificidades quanto às normas no que se refere ao processo de formação de atletas. Por exemplo, Galindo (2016) cita que o artigo 29 da Lei Pelé é claro ao impossibilitar relações empregatícias nas divisões de base, sendo permitidas, apenas, bolsas concedidas mediante pactos livres. Ainda, o autor explica que cabe ao clube formador um percentual que varia de $0,25 \%$ a $0,5 \%$ sobre as vendas futuras de jogadores por ele formados, a depender da idade dos atletas.

A ativação no intangível de gastos com atletas em formação é uma característica brasileira, dada a sua permissão através de dispositivos legais. Na Europa, apenas os atletas profissionais pertencem ao intangível, sendo os gastos na formação de atletas, de idades quaisquer, tratados como despesas do período (BASTOS; PEREIRA; TOSTES, 2007; GALVÃO; MIRANDA, 2016; CRUZ; SANTOS; AZEVEDO, 2010). Segundo Matos et al. (2015), esse fato ocorre em virtude de uma proibição da própria Union of European Football Associations (UEFA).

Martin e Johan (2014) criticam esse entendimento porque, segundo eles, grande parte dos elencos de clubes europeus é formado por atletas formados na base e, uma vez que os direitos de tais atletas são vendidos e geram receitas aos clubes, não faz sentido deixá-los de fora do ativo dos clubes.

\subsection{Estudos anteriores}

A literatura referente à contabilidade nas entidades desportivas futebolísticas em geral é composta por estudos que datam a partir do século XXI. Talvez isso ocorra devido à grande mutação de dispositivos legais a partir da década de 1990, como a Lei Zico, a Lei Pelé, a Resolução CFC n. ${ }^{\circ}$ 1.005/2004 e, ainda, a Lei n. ${ }^{\circ}$ 11.638/2007.

Paton et al. (2013) estudam o perfil das publicações existentes em periódicos Qualis-Capes entre 2004 e 2013 e verificam que o tema mais abordado nas pesquisas é a contabilização e a evidenciação dos direitos federativos e dos custos de formação de atletas. Além disso, o procedimento metodológico mais utilizado é a pesquisa exploratória.

Exemplos desse tipo mais comum de pesquisa na área são os estudos de Galvão e Miranda (2016) e Curvina e Nascimento (2014), que buscam identificar os clubes que melhor evidenciam os jogadores em seus demonstrativos, através de análises documentais. Araújo et al. (2013), em uma pesquisa similar, apontam que, em geral, os clubes evidenciam os ativos intangíveis de forma correta, exceto quanto ao teste de impairment.

Os achados de Matos et al. (2015), em sua pesquisa de natureza qualitativa, são de que as práticas contábeis dos clubes brasileiros estão de acordo com normas nacionais e internacionais de contabilidade. Isso está de acordo com as conclusões de Buesa e Araújo (2012) ao dizer que os quatro maiores clubes do estado de São Paulo estavam em conformidade com as normas contábeis, dados os demonstrativos de 2010.

Alguns estudos resultaram em informações específicas sobre os custos de formação de atletas. Lopes e Davis (2006), por exemplo, entendem que os custos de formação de atletas devem ser equiparados aos gastos com pesquisa e desenvolvimento, devido às suas similaridades. Cruz, Santos e Azevedo (2010) propõem um método mais simplificado para classificação de custos de formação de atletas devido à grande desconfiança acerca do cumprimento do requisito em decorrência de futuros benefícios econômicos por estes jovens atletas.

De acordo com Bastos, Pereira e Tostes (2007), no ano de 2004, os clubes brasileiros não classificavam os custos de formação de atletas em seu ativo imobilizado (de acordo com as normas vigentes à época) e, em contrapartida, os clubes europeus o faziam. Porém, conforme os achados de Holanda et al. (2012), entre 2006 e 2009, a divulgação sobre tais custos por clubes brasileiros de futebol cresceu continuamente, havendo, portanto, uma melhoria no disclosure.

Liszbinski et al. (2012), ao analisarem os demonstrativos de clubes da série A do futebol brasileiro, apontam uma grande representatividade dos jogadores da base no patrimônio dos clubes.

Destaque, ainda, para dois estudos de caso sobre o tema: Silva e Moraes (2010), que estudam as categorias de base do Grêmio Foot-Ball Porto Alegrense e Cruz (2012), que estuda especificamente a categoria sub-15 do Cruzeiro Esporte Clube. Ambos estudos apontam que investir nas categorias é fundamental para o sucesso técnico e financeiro dos clubes. 


\section{METODOLOGIA}

De acordo com Gil (2010), pesquisas explicativas são aquelas que concentram esforços na identificação de fatores que contribuem para a ocorrência de um fenômeno. Esta é a classificação deste trabalho, visto que objetiva explicar a relação entre os custos de formação dos atletas e seu impacto na marca dos clubes. Ainda, este estudo se vale de procedimentos quantitativos e positivistas, tendo em vista a realização de uma coleta de dados contábeis através de demonstrativos dos clubes e de valores das marcas dos clubes através de um estudo realizado por uma firma de consultoria e auditoria, além de tratamento e análise posterior dos dados (MARTINS; THEÓPHILO, 2009).

Como ferramenta para verificação da capacidade de explicação dos custos de formação dos atletas frente ao valor das marcas dos clubes, foi utilizada a técnica de análise de regressão. De acordo com Gujarati e Porter (2011), essa técnica visa estimar os valores da variável dependente através de valores previamente conhecidos em variáveis independentes.

Como visto anteriormente, os estudos acerca da contabilidade em entidades desportivas são, em grande maioria, do tipo qualitativo, valendo-se de técnicas como análise documental e pesquisa exploratória. Entretanto, para Corrar, Paulo e Dias Filho (2007), a análise de regressão, dado o seu viés de previsão, é frequentemente utilizada nas áreas de negócio. Como o objetivo final deste estudo é predizer os valores das marcas dos clubes, acredita-se que a aplicação dessa ferramenta seria mais adequada, além de ser inovadora frente aos habituais processos metodológicos da área.

Sendo assim, como variável dependente, foram selecionados os valores das marcas dos clubes. Tais valores foram obtidos através de um estudo realizado pela empresa de consultoria e auditoria BDO, consolidada no chamado grupo das “Big 5", em referência às cinco maiores empresas deste segmento no mundo. O estudo utilizado foi disponibilizado no ano de 2017, sendo essa a sua nona versão. O valor das marcas dos clubes é calculado através de informações diversas como o perfil dos torcedores, dados de marketing, tratamento de mídias sociais e, logicamente, informações econômicas dos clubes (BDO, 2017).

Já os custos de atletas em formação dos clubes, tratados daqui em diante como CAF e referentes à variável preditora, foram obtidos através dos demonstrativos financeiros publicados pelos clubes diretamente em seus websites. Dessa forma, a amostra é caracterizada como não-probabilística, dado o recurso de coleta dos dados (GUJARATI; PORTER, 2011).

A amostra inicial foi composta pelos clubes brasileiros da série A do futebol brasileiro entre os anos de 2013 e 2016 . A série A do campeonato brasileiro de futebol é composta por 20 clubes, portanto, a amostra inicial era de 80 observações.

O primeiro tratamento dos dados foi a eliminação de observações cujos dados eram insuficientes ou inexistentes, como, por exemplo, casos nos quais os clubes não divulgavam os custos das categorias de base. Após esse tratamento, restaram 68 observações completas.

Em seguida, foram eliminadas duas observações no tratamento dos outliers. De acordo com Gujarati e Porter (2011), outliers são valores discrepantes acima ou abaixo da maioria das observações e que podem interferir na análise do resultado, se não forem eliminados. Dessa forma, a amostra final foi composta por 66 observações de um total de 80 observações iniciais, representando, portanto, $82,5 \%$ do total possível.

Os dados das 66 observações foram empilhados (pooling), sendo a composição geográfica e cronológica dos clubes estudados apresentada da seguinte forma:

Quadro 1: Composição da amostra

\begin{tabular}{|c|c|c|c|c|}
\hline ANO & SUL & SUDESTE & NORDESTE & TOTAL \\
2013 & 5 & 9 & 1 & 15 \\
2014 & 6 & 7 & 3 & 16 \\
2015 & 7 & 8 & 1 & 19 \\
2016 & 6 & 10 & 3 & 66 \\
TOTAL & 24 & 34 & 8 & \\
\hline
\end{tabular}

Fonte: Elaborado pelo autor.

Explicada a seleção dos dados da variável dependente e da variável independente, o modelo de regressão linear final deste estudo foi:

$$
\mathrm{VMC}_{\mathrm{i}, \mathrm{t}}=\beta_{0}+\beta_{1} \mathrm{CAF}_{\mathrm{i}, \mathrm{t}}+\varepsilon
$$

Onde:

$V M C_{i, t}=$ Valor da Marca do Clube i, no tempo t;

$\beta_{0}=$ Intercepto;

$\beta_{1}=$ Coeficiente angular da regressão;

$C A F_{i, t}=$ Custo dos Atletas em Formação do clube i, no tempo t;

$\varepsilon=$ Resíduos da regressão. 
A hipótese formulada, representando o objetivo geral do estudo foi:

H1: Os investimentos feitos nas categorias de base dos clubes de futebol do Brasil possuem relação positiva com o valor das marcas desses clubes.

Dada a exigência dos pressupostos da normalidade dos resíduos e da homocedasticidade dos resíduos, foram utilizados, respectivamente, os testes de Jarque-Bera e Breusch-Pagan.

Foi definido previamente que, havendo o problema de heterocedasticidade dos resíduos, seria feita a correção de White, indicada por Gujarati e Porter (2011) como uma técnica de ajuste da consistência dos coeficientes para tal problema. Quanto à normalidade dos resíduos, em caso de violação do pressuposto, este seria relaxado com base no Teorema do Limite Central, dado o tamanho da amostra (CORRAR; PAULO; DIAS FILHO, 2007).

Além disso, como análise complementar, foi efetuado um teste de diferença de médias para as variáveis estudadas com a intenção de verificar se há diferença estatisticamente significante entre as médias dos custos de formação dos atletas e dos valores das marcas dos clubes de acordo com a região à qual esses clubes pertencem.

Os testes dos pressupostos bem como as regressões em si foram efetuados através do software Gretl®, mantendo sempre um índice de confiança de $99 \%$. Já os testes de diferenças de médias foram efetuados no software IBM SPSS $®$, em sua versão de número 22 , sob um nível de confiança de $95 \%$.

\section{ANÁLISE DOS RESULTADOS}

O pressuposto da normalidade dos resíduos foi violado para um nível de significância de 1\%, porém, dado o Teorema do Limite Central e a amostra de 66 observações, o pressuposto foi relaxado. Já o pressuposto da homocedasticidade dos resíduos foi atendido perfeitamente ao nível de confiança de 99\%. Em seguida, são apresentados os resultados obtidos pela regressão:

Quadro 2: Resultados do modelo $\mathrm{VMC}_{\mathrm{i}, \mathrm{t}}=\beta_{0}+\beta_{1} \mathrm{CAF}_{\mathrm{i}, \mathrm{t}}+\varepsilon$

\begin{tabular}{|c|c|c|c|c|}
\hline \multicolumn{5}{|c|}{ Painel A } \\
\hline & Coeficiente & Erro Padrão & Razão-t & p-valor \\
\hline Constante & $6,78072 \mathrm{e}+07$ & $5,86756 e+07$ & 1,1556 & 0,2521 \\
\hline CAF & 29,2096 & 5,09101 & 5,7375 & $<0,0001$ *** \\
\hline \multicolumn{5}{|c|}{ Painel B } \\
\hline $\mathbf{R}^{2}$ & 0,339652 & $\mathbf{R}^{2}$ ajustado & \multicolumn{2}{|c|}{0,329334} \\
\hline$F(1,58)$ & 32,91862 & P-valor(F) & \multicolumn{2}{|c|}{$2,83 e-07$} \\
\hline
\end{tabular}

Fonte: Elaborado pelo autor

Fica perceptível, portanto, que o modelo como um todo é estatisticamente significativo ao nível de significância 1\%, uma vez que o p-valor(F) foi inferior a 0,01. Ainda, pode-se verificar que, para a amostra selecionada, o modelo possui um poder de explicação de, aproximadamente, $34 \%$ do valor das marcas dos clubes brasileiros de futebol da série A.

Dessa forma, a hipótese geral do estudo (H1) pode ser confirmada através dos resultados obtidos. O modelo, que é estatisticamente significativo com 99\% de confiança, demonstra que os investimentos nas categorias de base explicariam quase $34 \%$ dos valores das marcas dos clubes de futebol do Brasil.

Considerando a predominância de estudos correlatos de natureza qualitativa (PATON et al., 2013), esse achado torna-se singular por meio de sua mensurabilidade, em respeito ao processo metodológico quantitativo. Isso pode ser corroborado com a afirmação de Matos et al. (2015) de que o futebol, atualmente, é um verdadeiro negócio, em conjunto com a explicação de Silva e Moares (2010) de que os custos na formação de atletas deveriam ser tratados com afinco por representarem verdadeiros investimentos dos clubes e, Cruz (2012), que afirma serem cada vez maiores tais investimentos por parte de clubes brasileiros. Somente um alicerce de resultados quantificáveis seria capaz de realizar tal conexão de ideias e validar (ou não) uma hipótese de estudo similar àquela que foi proposta neste trabalho.

Analisando a variável explicativa (CAF), constata-se que essa é estatisticamente significativa a um nível de $99 \%$ de confiança, visto que seu p-valor é inferior a 1\%. É possível inferir, ainda, que tal variável está positivamente relacionada à variável de resposta (VMC). Dado o coeficiente angular da CAF, é possível concluir que, para a amostra observada, o aumento de uma unidade no investimento de CAF gera um aumento de, aproximadamente, 29 unidades no valor de mercado dos clubes. Esse resultado está de acordo com os achados de Cruz (2012) e Silva e Moraes (2010), quando afirmam que os investimentos feitos nas categorias de base estão positivamente relacionados ao resultado financeiro dos clubes.

O primeiro passo para a efetuação dos testes de diferenças de média, dispostos como análise adicional deste trabalho, foi a realização do teste de normalidade. Respeitando os ensinamentos de Corrar, Paulo e Dias Filho (2007), o teste de Kolmogorv-Smirnov foi utilizado para casos nos quais o número de observações das subamostras foi maior que 30 e, em casos contrários, foi utilizado o teste de Shapiro-Wilk. 
Para a variável VMC, o teste não apontou normalidade de forma unânime para as três regiões (Sul, Sudeste e Nordeste), portanto, foi necessária a utilização do teste não paramétrico Kruskal-Wallis.

Quadro 3: Resultados da diferença de médias do VMC

\begin{tabular}{|cc|}
\hline & VMC \\
Qui-Quadrado & 15,777 \\
Significância Sig. & 0,000 \\
\hline
\end{tabular}

$$
\text { Fonte: Elaborado pelo autor }
$$

De acordo com o resultado, é possível afirmar que ao menos uma região apresenta diferença de média estatisticamente significativa em relação às outras para um nível de confiança de 95\%. Em seguida, são apresentados os testes par a par de Mann-Whitney para obtenção de informações mais analíticas.

Quadro 4: Resultados da diferença de médias par a par do VMC

\begin{tabular}{|ccc|}
\hline \multicolumn{2}{|c|}{ Nordeste - Sudeste } & \\
U de Mann-Whitney & 29,000 \\
$\mathbf{Z}$ & & $-3,427$ \\
Significância Sig. (Bicaudal) & 0,001 \\
\hline & Nordeste - Sul \\
\hline U de Mann-Whitney & 60,000 \\
$\mathbf{Z}$ & & $-1,567$ \\
Significância Sig. (Bicaudal) & 0,117 \\
\hline & Sudeste - Sul & \\
\hline U de Mann-Whitney & & 229,000 \\
$\mathbf{Z}$ & & $-2,826$ \\
Significância Sig. (Bicaudal) & 0,005 \\
\hline
\end{tabular}

Fonte: Elaborado pelo autor

É possível inferir, através da estatística do teste de Mann-Whitney, que só há diferença estatisticamente significativa de médias do valor das marcas dos clubes, respeitando o nível de confiança de 95\%, quando a região Sudeste está presente no par de regiões observado. Isso parece estar de acordo com os achados de Maia, Cardoso e Ponte (2013) de que os clubes dessa região são os mais valiosos do país.

Diferentemente da variável VMC, para a variável CAF, o teste de normalidade indicou que se poderia aceitar a hipótese nula, sendo assim, foi utilizado o teste paramétrico ANOVA. Ressalta-se, ainda, que a utilização desse teste está de acordo com o resultado obtido no teste de Levene, que teve a hipótese nula aceita, ou seja, havia igualdade de variâncias para o item observado. Os resultados da ANOVA e do teste de Bonferroni foram:

Quadro 5: Resultados da ANOVA e do teste de Bonferroni para CAF

\begin{tabular}{|ccc|}
\hline \multicolumn{2}{|c|}{ Painel A - ANOVA } & Sig. \\
CAF & $\mathbf{Z}$ & 0,040 \\
\hline Par & 3,400 & \\
\hline Nordeste - Sudeste & Painel B - Bonferroni & Sig. \\
Nordeste - Sul & Diferença Média & 0,556 \\
Sudeste - Sul & $-3398215,978$ & 1,000 \\
\hline
\end{tabular}

Fonte: Elaborado pelo autor

Observando os resultados, constata-se, através da ANOVA, que, em relação aos custos de formação de atletas, ao menos uma das regiões possui média estatisticamente significativa diferente das outras para um nível de confiança de 95\%. E, de acordo com os resultados do teste de Bonferroni, é possível afirmar que só existe diferença estatisticamente significativa nos investimentos em atletas em formação entre as regiões Sudeste e Sul. 


\section{CONCLUSÕES}

Este trabalho teve por objetivo verificar se o investimento feito pelos clubes brasileiros de futebol em suas categorias de base possuem reflexo positivo no valor de suas marcas. Alguns estudos anteriores apontam que, dadas as dificuldades para a contratação de novos atletas devido às altas cifras envolvidas, os clubes do Brasil tomaram como alternativa o investimento em jogadores jovens que possam vir a servir a equipe de profissionais no futuro.

Os jogadores, adquiridos junto a outros clubes ou formados internamente, devem estar registrados no ativo Intangível, de acordo com as normas contábeis vigentes, porém, de acordo com a literatura observada, na Europa, apenas os jogadores profissionais são tratados dessa forma, sendo os custos de formação de atletas tratados como despesas do período.

Fato é que, no Brasil ou na Europa, estudos apontam que jogadores formados nas categorias de base representam grande parte do patrimônio dos clubes, sendo considerados fundamentais para futuros retornos técnicos quando da sua chegada à categoria profissional e também para retornos financeiros, em caso de venda de seus direitos federativos.

Embora haja uma consistente literatura acerca do tema, não foram identificados resultados derivados de procedimentos metodológicos quantitativos, fato esse que impossibilita a mensuração dos reflexos de maiores investimentos na formação de atletas. Com isso, através de uma regressão linear, na qual os Custos com Atletas em Formação (CAF) foram tratados como a variável preditora do Valor das Marcas dos Clubes (VMC), foi testada a hipótese de que os investimentos feitos nas categorias de base dos clubes de futebol do Brasil estariam positivamente relacionados ao valor das marcas desses clubes.

O modelo como um todo e a variável explicativa em si foram estatisticamente significativos a um nível de confiança de $99 \%$, portanto, a hipótese geral do estudo foi aceita. Além disso, o modelo apresenta um poder explicativo de, aproximadamente, $34 \%$ do valor das marcas dos clubes. A variável independente está positivamente relacionada à variável de resposta, havendo um aumento de quase 29 unidades dessa, em virtude do aumento de uma unidade daquela. Os resultados obtidos estão de acordo com estudos anteriores aqui citados, que apontam uma relação positiva entre os investimentos feitos na formação de atletas e os resultados financeiros obtidos.

Como análise complementar, foram efetuados testes de diferença de médias das variáveis VMC e CAF, de acordo com as regiões dos clubes. Os resultados apontaram que só existe diferença estatisticamente significativa de médias de VMC quando a região Sudeste está envolvida na comparação. Aparentemente, isso está de acordo com a ideia de que os clubes dessa região são mais valiosos. Em relação aos custos de atletas em formação, é possível afirmar que, para a amostra observada, só existe diferença estatisticamente significativa desses investimentos entre as regiões Sul e Sudeste.

Uma possível limitação deste trabalho é que alguns clubes não apresentavam os dados necessários para a pesquisa e, talvez, esses dados fossem relevantes para o resultado final. Outra limitação diz respeito à variável de resposta do estudo que, embora elaborada e divulgada por uma empresa de grande porte, não é considerada como científica metodologicamente.

Espera-se que este trabalho contribua para o campo das pesquisas de Contabilidade Desportiva, em especial as que tratam sobre o futebol, ao utilizar uma metodologia atípica nesse cenário (tradicionalmente qualitativo) para corroborar entendimentos anteriores de que os clubes deveriam aumentar seus investimentos em suas categorias de base visando retornos financeiros, uma vez que os resultados apontam que tais investimentos agregam valor às suas marcas.

Como sugestão para trabalhos posteriores, é indicada a execução de metodologia similar em outros intervalos cronológicos e/ou outras nações, a fim de verificar se os resultados são recorrentes em condições diversas.

\section{REFERÊNCIAS}

ARAÚJO, P. A. et al. A evidenciação dos ativos intangiveis dos clubes de futebol Corinthians, Flamengo, Palmeiras, Santos, São Caetano e São Paulo. Revista Brasileira de Contabilidade, n. 203, p. 31-43, 2013.

BASTIDAS, M. G.; BASTOS, F. DA C. A Lei de incentivo fiscal para o desporto e a formação de atletas no Brasil. Revista Intercontinental de Gestão Desportiva, v. 1, n. 2, p. 111-121, 2011.

BASTOS, P. S. S.; PEREIRA, R. M.; TOSTES, F. P. Uma contribuição para a evidenciação do ativo intangível - atletas - dos clubes de futebol. Pensar Contábil, v. 9, n. 36, p. 1-16, 2007.

BDO. $9^{\circ}$ Valor das marcas dos clubes brasileiros. Disponível em: <https://www.bdo.com.br/pt-br/publicacoes/publicacoes/9\%C2\%BA-valor-das-marcas-dos-clubes-brasileiros>. Acesso em: 24 set. 2017.

BUESA, N. Y.; ARAÚJO, S. F. DE. Contabilidade Esportiva: A Adoção da Resolução n. ${ }^{\circ} 1.005$ / 2004 nos Clubes Paulistas de Futebol Profissional. Revista Eletrônica Gestão e Negócios, v. 3, n. 1, p. 1-24, 2012.

COMITÊ DE PRONUNCIAMENTOS CONTÁBEIS. CPC 00 - Pronunciamento Conceitual Básico - Estrutura Conceitual para Elaboração e Divulgação de Relatório Contábil-Financeiro. Disponível em: <http://static.cpc.mediagroup.com.br/Documentos/147_CPC00_ R1.pdf>. Acesso em: 29 out. 2017.

CORRAR, L. J.; PAULO, E.; DIAS FILHO, J. M. Análise Multivariada: para os cursos de Administração, Contábeis e Economia. São Paulo: Atlas, 2007. 642 p.

CRUZ, R. M. A Formação de Atletas de Futebol: Um estudo na categoria sub-15 do Cruzeiro Esporte Clube, Belo Horizonte, MG. Revista Brasileira de Futebol e Futsal, v. 4, n. 13, p. 189-194, 2012.

CRUZ, S. N. DA S. R. A. Mensuração dos direitos resultantes da formação. Contabilidade e Gestão, n. 5, p. 73-109, 2007. 
CRUZ, S. N. DA S. R. A.; SANTOS, L. L.; AZEVEDO, G. M. DO C. Valorização do direito desportivo resultante da formação. Revista de Educação e Pesquisa em Contabilidade, v. 4, n. 1, p. 60-83, 2010.

CURVINA, V. M. G.; NASCIMENTO, D. V. R. DO. Custos dos direitos federativos nos clubes brasileiros. In: XXI Congresso Brasileiro de Custos. Anais... Natal: 2014. p. 1-15.

GALINDO, C. H. A. Os direitos dos atletas em formação e a Lei 6.354/76: consequências das transferências entre clubes. Revista Cientifica Intraciência, n. 11, p. 1-26, 2016.

GALVÃO, N. M. DOS S.; MIRANDA, L. C. Participação e Evidenciação de atletas nos Demonstrativos de Clubes de Futebol Brasileiro. Revista de Gestão, Finanças e Contabilidade, v. 6, n. 1, p. 112-131, 2016.

GIL, A. C. Como elaborar projetos de pesquisa. 5. ed. São Paulo: Atlas, 2010. 184 p.

GUJARATI, D. N.; PORTER, D. C. Econometria básica. 5. ed. Porto Alegre: AMGH, 2011. 924 p.

HOLANDA, A. P. et al. Determinantes do nível de Disclosure em clubes brasileiros de futebol. Revista de Contabilidade do Mestrado em Ciências Contábeis da UERJ (online), v. 17, n. 1, p. 2-17, 2012.

LISZBINSKI, B. B. et al. Custo de formação de atletas em entidades desportivas profissionais: um estudo sobre a aderência às normas contábeis. In: XIX Congresso Brasileiro de Custos. Anais...Bento Gonçalves: 2012. p. 1-14.

LOPES, H. A.; DAVIS, M. D. O ativo jogador de futebol. Pensar Contábil, v. 8, n. 33, p. 1-10, 2006.

MAIA, A. B. G. R.; CARDOSO, V. I. da C.; PONTE, M. R. Práticas de disclosure do ativo intangível em clubes de futebol. Revista de Administração, Contabilidade e Economia da FUNDACE, v. 4, n. 1, p. 1-17, 2013.

MARTIN, B.; JOHAN, W. Accounting and disclosure of football player registrations: do they present a true and fair view of the financial statements? A study of top european football clubs. 2014. $57 \mathrm{f}$. Tese (Mestrado) - Curso de Contabilidade, Jönköping University, Jönköping, 2014. Disponível em: <http://www.diva-portal.org/smash/get/diva2:721716/FULLTEXT01.pdf>. Acesso em: 26 out. 2017.

MARTINS, G. de A.; THEÓPHILO, C. R. Metodologia da Investigação Cientifica para Ciências Sociais Aplicadas. 2 ed. São Paulo: Atlas, 2009. $247 \mathrm{p}$.

MATOS, T. M. P. DE et al. Custo de Formação de Jogadores de Futebol: análise das práticas contábeis adotadas no Brasil e na Europa. In: VI Congresso Nacional de Administração e Contabilidade - ADCONT. Anais...Rio de Janeiro: 2015. p. 1-15.

PATON, C. et al. Contabilidade e Agremiações Esportivas de Futebol Profissional: Uma Análise da Publicação Científica Contábil em Periódicos QUALIS no Período de 2004 a 2013. In: $5^{\circ}$ Congresso UFSC. Anais...Florianópolis: 2013. p. 1-16.

REZENDE, A. J.; FACURE, C. E. F; DALMÁCIO, F. Z. Práticas de Governança Corporativa em Entidades Sem Fins Lucrativos. In: CONGRESSO USP CONTROLADORIA E CONTABILIDADE, 9., 2009, São Paulo. Anais... São Paulo: USP, 2009. p. 1-16.

SILVA, L. M. DA; MORAES, M. M. Contabilidade das entidades desportivas: um estudo sobre a apuração do custo contábil do atleta de futebol em formação do Grêmio Foot-Ball Porto Alegrense. In: XVII Congresso Brasileiro de Custos. Anais...Belo Horizonte: 2010. p. 1-16. 